\title{
Analysis of Bilibili New Year's party
}

\author{
Puxiu JIA ${ }^{1, *}$
}

\author{
Lingnan University MA in Creative and Media \\ Industries, New Territories, Tuen Mun, Hongkong,China \\ Email: jia_puxiu2021@163.com
}

\begin{abstract}
The 2020 Bilibili video platform New Year's party breaks from China Radio and TV Station Spring Festival Gala and Graded TV New Year's Eve concert, which is mainly reflected in the viewing form of the gala, the way of program interpretation, and the invitation of guests. The innovation of this party broke through people's new understanding of the format of the show. The show respects the audience and respects the difference. Through the show, the inclusiveness of the Bilibili platform is reflected.Bilibili adheres to the original intention of the platform to establish a cultural community of young people as a starting point to respect multicultural interpretation and mutual integration, such as the integration of the second dimension and the national style, the integration of tradition and fashion.

This article starts with the research on the content of the Bilibili New Year's Gala. It conducts a detailed analysis based on the innovation of the party's theme and broadcast format as the starting point. At the same time, the Bilibili New Year's Gala will compare with traditional gala (for example, Spring Festival Gala, various satellite TV New Year's Eve concerts). For comparison, the main directions of comparison include the audience of the evening party, the broadcasting form of the evening party, the selection of the program's guests, and the way of performing the program. Meanwhile, this research will analyze the relationship with the new generation and future development based on the platform attributes of Bilibili.
\end{abstract}

Keywords: Bilibili, New Year's Party, New Generation.

\section{INTRODUCTION}

Since Bilibili's Danmu culture entered the public's field of vision, every appearance of Bilibili will bring unprecedented perception and thinking to the audience. The 2020 Bilibili New Year's Party is the second time that the Bilibili platform has been held. The difference from the first part is that the background of the era is different, and the content and themes of the program are innovative. Popularity, The emergence of the Bilibili New Year's party in 2020 can be understood as another media event, which has caused a certain degree of social influence and discussion on social topics, which can be explained by the response from the platform to the platform users to this evening party. This article only discusses and analyzes the 2020 Bilibili New Year Party as the primary research object:

1.We will start with the research on the Bilibili New Year's Party's main broadcast content, conduct a detailed study based on the innovation of the party's theme and broadcast format as the starting point, and compare the traditional Chinese gala with it.
2.We will compare and explain the past media events with the New Year's party to prove whether the party is a media event worth giving examples.

3.It will analyze the relationship with the new generation and future development based on the platform attributes of Bilibili.

The excellent culture of the Bilibili platform goes out of the circle. To accurately understand the preferences of the platform audiences who has always been an essential part of the psychological research of the audience, which in the development of the media industry. Analysis of the content of the New Year's party program to understand the audience's preferences and lay the foundation for future program innovation.

\section{THE EMERGENCE OF THE PARTY}

The 2020 Bilibili New Year's party is very different from the audience's standard party, from the theme to the broadcast format to the interactive mode. Whether it is the China Media Group Spring Festival Gala Evening 
or the New Year's Eve concerts of each David TV are different.

The "Spring Festival Gala" is a comprehensive art gala organized by China Central Radio and Television Station every New Year's Eve to celebrate the New Year. Originated in 1979, it was officially opened in 1983[1] and was positioned as a national project in 2014[2]. The gala covers a variety of art forms such as sketches, songs, singing and dancing, acrobatics, magic, opera, cross talk, etc. The stars gathered in the Spring Festival Gala are also leaders in various art industries. The broadcast time of the Spring Festival Gala is every year on New Year's Eve (the time of New Year's Eve varies from year to year, and the specific events are subject to the calendar date). New Year's Eve is a day of reunion for every Chinese family, and it is a Chinese custom. Here, the New Year must have a family reunion. The whole family sits together and eats dumplings to watch the Spring Festival Gala. Therefore, its existence is no longer the concept of a literary evening but an iconic symbol that has already symbolized reunion in the hearts of Chinese people. The gala, almost the same as the Spring Festival Gala, is a New Year's Eve concert. When the year 2000 came, the concept of New Year's Eve appeared vaguely in the TV media for the first time.

During this year, China joined the world to welcome the arrival of the "Millennium" [3]. The first New Year's Eve concert in mainland China was held by Hunan Satellite TV in 2005 and then by Dragon TV in 2006. So far, the "battle" of the New Year's Eve concert has been launched among many TV stations. The broadcast time of the New Year's Eve concert is fixed, from the evening of December 31st to the next day. For the audience, it is a farewell to the past year, a new beginning of the new year, and it is also an audio-visual feast. The difference between the New Year's Eve concerts of each satellite TV is that different singers/movie stars will be invited to sing songs, and the same is that the broadcast date is the same. The program content format is also singing and interacting with the audience. The difference from the Spring Festival Gala is the time/structure of the program. The same as the Spring Festival Gala is that it is broadcast on radio and television channels and will be broadcast simultaneously on some mainstream video platforms later in development. The next mentioned is the Bilibili platform (hereafter referred to as b station) that allows the public to refresh the party's cognition through the video platform.

B Station is the same as the first two types of evening parties in that it is also a cultural evening. The same thing as the New Year's Eve concert is that its broadcast time is also on December 31st. It also invites singers/movie stars to sing and dance. The biggest difference between the former 2 is that it has different broadcasting platforms/different audience groups,/program content is very different. First of all, the broadcasting platform of $b$ station is itself. It is not affiliated with the central government. The audience cannot find it in search of TV channels, and it is not output in the way of live broadcast, but it will be recorded in advance and then recorded in episodes. Broadcast, respectively, sunset/monthly rise/starry. The content of the program is no longer a purely singing and dancing interpretation of the well-known popular stars. The content of the New Year program at b station integrates diversified elements and achieves a mix and match. For example, the integration of the second dimension and the national style, the integration of tradition and popularity, People are familiar with major adaptations of songs, etc. Even in the era of the epidemic, online and offline fantasy linkages can still be achieved. All these credits are due to the barrage culture, which enables online and offline communication through the barrage.

The New Year's party at station b is called "the party that knows the most about young people," There are many different voices to discuss. The stage specifications have also been fully upgraded. The threedimensional and rich lifting stage is matched with AR, $\mathrm{MR}$, and XR vision. Technology, with the help of $4 \mathrm{~K}$ ultra-high-definition picture quality and Dolby Atmos production standards, brings a full range of audio-visual upgrade experiences to the audience in front of the screen. At the same time, the party also set up branch venues in 4 cities, following the "Spring Festival Gala" branch venue model, multiple platforms celebrating the New Year, just like the three themes of this evening party, welcoming the glory of the new year's sun and meeting the challenges, Create a miracle bravely.

\section{MEDIA EVENTS: “DANMU” CULTURE/INTERNET TERMS/POPULARITY}

Daniel Dayan and Elihu Katz defined in "Media Events" "the festive viewing of television, that is, the historical events of live television that make the Chinese and even the world hold their breath" for 2020 Bilibili The broadcast of the New Year's party reflects on the media events.

First of all, the audience of Bilibili is vast, and all of them are the younger generation. The younger generation of online users accepts new things and disseminates videos quickly. Secondly, one of the reasons for the vast audience is that the content section of the Bilibili platform is also pervasive, divided into four categories according to the content section. The first is ACG-related content (a barrage video sharing site that started with ACG-related content). ACG is the English acronym for Japanese animation (Anime), comics 
(Comics), and video games (Games)Secondly, it contains multiple partitions, such as Live Broadcast, Classroom, Animation, Music, Dance, Games, Knowledge, Digital, Life, Food, VLOG, and others. Users can watch videos in their favorite partitions, and they can also perform video viewing Published.In addition, there are also membership purchases, thematic centers, the district leaderboards, event centers, tiny black houses, music PLUS, game centers (especially the game publishing platform with the login interface of Bilibili agents), and the area of game events. . In addition to the video, Bilibili also operates many games such as "Fate/Grand Order" and "Benghuai Academy $2 "$.

The word "danmu" is a Chinese word that first appeared in the military field and in Japanese. It has the same meaning as Chinese and was later used in certain shooting games.The term "danmu" is used to watch videos, mainly from the instant comment system of some animation websites. In Japan, people call this state "barrage" only when many of the same comments appear on the screen.After this interactive form was introduced to mainland China, because the comment system made the effect of the comment drifting across the screen look like a flying bullet, people called the impact of this kind of comment "danmu."Because the word "drag" originated from bullets, the pronunciation is considered to be dànmù, but some people mistakenly pronounce it as tánmù.

Using the "danmu" function, viewers can post their own comments while watching the video and will instantly display the subtitles that slide past when all viewers watch the video at that point in time, thereby increasing the viewer's awareness. Bilibili provides the following three commonly used barrage modes: rolling barrage, top barrage, and bottom barrage.

The font of the barrage can be changed in color. Choose a barrage with a fixed top end, a fixed bottom end, and a right-to-left movement. The font size is limited to "small" and "medium," and you can post comments at the bottom of the video page. The barrage and the video content itself form two individuals. The video itself is one content, and the content of the barrage is another individual. The user expresses opinions on the top of the video, and a certain discussion will be formed in the barrage area. There are some Internet terms that can even be said to be the emergence of a special language for "danmu," such as "yeqinghaiand "huoqianliuming." This kind of special language for barrage is not only used in the barrage area of the video but also in people's daily life., Is a new type of network language, and it is used in many places in the New Year's party. The arrangement and creation of many programs are also innovated with the network language of "danmu."
The three development stages of "danmu".The first to appear the "danmu" function is the sharing site Nico Nico from Japan.This is the first stage of the history of "danmu" which originated in Japan.Later, AcFun, which was spread in China, was also the first “ danmu" website, the boss of the second dimension, and is now the birthplace of Bilibili.

At that time, most of AcFun's audience was born in the 1990s, and they often risked being beaten by their parents by going to Internet cafes to carry various videos and send consultations to AcFun. Before 2014, AcFun had always been the domestic boss. The " danmu" system is also very comprehensive, you can post comments, and you can selectively publish anonymously. This is the second stage of the history of "danmu" development, from abroad to domestic.In 2014, AcFun was maliciously attacked by hackers and lost the passwords of millions of users. Since then, it has gone up and down and slowly disappeared from the audience. At the same time, the decline of AcFun also brought the rise of bilibili, and we ushered in the first era of "danmu" At the same time, this is also the third stage of the historical development of the "danmu", beginning with Bilibili.

As far as the show type is concerned, b station has made many innovations: the innovation of the program content, the innovation of the broadcasting form, and the innovation of the interactive mode. For the audience, the space boundary for viewing was first broken. The audience directly participated in the entire event. Even under the influence of the epidemic, they can still output their love for the party through the "danmu" . This is precisely $b$ Stand at the breakthrough point of the sudden emergence. Based on the development of " danmu” culture, a lot of Internet vocabulary has been circulated in $b$ station. Internet terms often express special meanings in specific media, but they do not have teaching qualifications. Generally speaking, they are primarily used in people's daily lives. To describe a state, an emotion, etc. The operation mode of $b$ station itself and the platform itself are highly anticipated by the public and have a perfect and precise audience. It is based on the 2019 evening party, so it arose before the broadcast of the 2020 New Year's party video at b station. A lot of netizens' expectations.

To sum up, The combination of Bilibili's own platform attributes, the age of the audience, and the selfcontained barrage culture has contributed to Bilibili's new year's party innovations. There are many innovative ideas that can be applied to the party. At the same time, through the platform every time. The data in this area understand the main trends of the audience, combined with the psychological research of the audience, is more guiding, understands the preferences of the audience, and understands the audience's culture. Innovation 
through these is even more innovative.the New Year's party at b station in 2020 constitutes a media event, breaking through the spatial dimension and breaking the time limit, and at the same time, it has a certain degree of "famousness" before it is broadcast.

\section{CONCLUSION}

The response to this New Year's party is also inseparable from several external factors and social background. For the audience, the program format of the Spring Festival Gala and the Satellite TV New Year's Eve concert has been single and caused visual fatigue. Under such a background, the first b station has a favorable condition, and its room for innovation is enormous. In addition, no matter what choice $b$ station makes, its results are more pros than cons in this game. First, the audience will watch with the same psychology as the Spring Festival Gala/New Year's Eve concert, as long as they break the rationalization. That is it.The Bilibili platform gave birth to a unique form of the online platform that brought together young people' $\mathrm{s}$ ideas.

In such a media era where traditional media and new media alternately appear, traditional media is facing transformation and innovation. At the same time, emerging media are also using their own media attributes and audience preferences to create a lot of novel content. In my opinion, this is A good era of communication is also a very good medium of communication. Whether it is a niche subculture or a well-known mainstream culture, mutual fusion and collision will be a brand-new fusion product. Just like media fusion, this is a win-win situation. the result of.

The Bilibili platform has nurtured a unique form of an online platform that brings together the ideas of young people. Young people also realize themselves through this platform. Users can express what they want, upload their own creative videos, and at the same time. Learning through this platform integrates entertainment, technology, culture, and other elements together. It is a diversified platform. Just like many shows in the evening party, people' $\mathrm{s}$ unexpected performance forms are fused together to form a new concept. Let people feel refreshed and bright in front of their eyes.

But at the same time, there is another question worth pondering and discussing: will Bilibili's niche culture and mainstream culture want to merge with the traditional impression of the evening party again? Bilibili's New Year's party captured the audience's preferences when it first started innovation and integration, but with the intervention of significant brand sponsors, when the mainstream and capital of the entire Internet industry invaded, What should we do at the New Year's party? This is a question we will think about and discuss in the future

\section{REFERENCES}

[1] And Li Zhinian sees the Spring Festival Gala 19832013. The more difficult it becomes, the more difficult it becomes. People's Daily Online [reference date 2017-11-10]

[2] Executive Director of the Spring Festival Gala: The first of the Spring Festival Gala is positioned as a national project. Sina Entertainment [cited date 2017-11-09]

[3] Analysis of the origin and current situation of the TV New Year's Eve party in mainland China . People's Daily Online. 2012-3-16 [Reference date 2020-01-01]

[4] Li Luping. From "xi" to "Yeh Qinghui": An analysis of the identity and development of youth subculture from the annual barrage of station $B$ in 2017-2020[J].New Generation,2021(05):50-56+35.

[5] Zhou Xing. China's "Spring Festival Gala" should rebuild its core cultural standpoint_-Analysis of the trend and development of the Chinese New Year Gala from the perspective of cultural soft power construction[J].New Art,2010,31(04):86$90+76$

[6] Mei, F., 2021. Bullet chats in China: Bilibili, language, and interaction.

[7] SAGE Journals. 2021. Towards a historical understanding of the media event - Espen Ytreberg, 2017. [online] Available at: <https://doi.org/10.1177/0163443716643155> [Accessed 18 November 2021].

[8] Bilibili.com. 2021. Read the growth history of bilibili in one minute. [online] Available at: <https://www.bilibili.com/read/cv886599/>

[Accessed 18 November 2021].

[9] SAGE Journals. 2021. Media events in contexts of transition: sites of hope, disruption and protest Martha Evans, 2018. [online] Available at: <https://doi.org/10.1177/0163443717726012> [Accessed 18 November 2021].

[10] M.gmw.cn. 2021. The New Year's Eve party at station B rings the bell in Wuhan, cultural integration illuminates the New Year's hope. [online] Available at: <https://m.gmw.cn/baijia/2021-01/01 /1301993327.html> [Accessed 19 November 2021]. 
[11] Kns.cnki.net. 2021. 2021: Media choices and choices in the trend-China Knowledge Network. [online]

Available<http://kns.cnki.net/kcms/detail/Detail.as px ?dbname $=$ CJFDAUTO\&filename $=$ QNJZ202101 $012 \& v=>$ [Accessed 17 November 2021].

[12] Pradsmadji, S. and Irwansyah, I., 2021. Media Convergence in the Platform of Video-on-Demand: Opportunities, Challenges, and Audience Behaviour.

[13] Keane, M., 2013. Creative Industries in China. Hoboken: Wiley.

[14] Huang, W. and Li, X., 2019. The E-commerce Law of the People's Republic of China: E-commerce platform operators liability for third-party patent infringement. Computer Law \& Security Review, 35(6), p.105347. 